\title{
EXISTENCE RESULTS OF $l$-POINT BVP FOR HIGHER ORDER DIFFERENTIAL EQUATIONS WITH ONE-DIMENSION $p$-LAPLACIAN
}

\author{
Y. LIU and Z. GUI
}

Received February 23, 2007 and, in revised form, January 29, 2008

\begin{abstract}
Motivated by Gupta [9] and Garcia-Huidobro, Gupta, Manasevich [5], the solvability of multi-point boundary value problems consisting of higher-order differential equations and multi-point boundary conditions are studied in this paper, respectively. Results show us that known theorems are complemented and improved. Numerical examples are presented to demonstrate the main theorems.
\end{abstract}

\section{INTRODUCTION}

In [13], [14], [15], [16], Liu and Yu studied the solvability of multi-point boundary value problem at resonance consisting of the second-order differential equation

$$
x^{\prime \prime}(t)=f\left(t, x(t), x^{\prime}(t)\right)+e(t), \quad 0<t<1,
$$

2000 Mathematics Subject Classification. Primary: 34B15.

Key words and phrases. Solution, resonance, multi-point boundary value problem, higher order differential equation with $p$-Laplacian, numerical example.

Supported by Natural Science Foundation of Guangdong Province (No: 7004569) and Natural Science Foundation of Hunan Province (No: 06JJ5008)

ISSN 1425-6908 C Heldermann Verlag. 
and one of the following boundary value conditions

$$
\begin{aligned}
& x^{\prime}(0)=0, \quad x^{\prime}(1)=\sum_{i=1}^{l} \beta_{i} x^{\prime}\left(\eta_{i}\right), \\
& x(0)=0, \quad x^{\prime}(1)=\sum_{i=1}^{l} \beta_{i} x^{\prime}\left(\eta_{i}\right),
\end{aligned}
$$

where $0<\eta_{i}<1$, and $\beta_{i} \in \mathbb{R}$ and $f$ is continuous and $e \in L^{1}[0,1]$. The following results were proved.

Theorem $L \boldsymbol{Y}_{\mathbf{1}}\left(\left[14\right.\right.$, Theorem 3.8]). Suppose $\sum_{i=1}^{l} \beta_{i}=1$ and $\sum_{i=1}^{l} \beta_{i} \eta_{i}$ $\neq 1$ and

$\left(L_{1}\right)$ There is $M>0$ such that for each $x \in D(L)$ if $|x(t)|>M$ for all $t \in[0,1]$ one has

$$
\sum_{i=1}^{l} \beta_{i} \int_{\eta_{i}}^{1}\left(f\left(t, x(t), x^{\prime}(t)\right)+e(t)\right) d t \neq 0 .
$$

$\left(L_{2}\right)$ There is $M^{*}>0$ such that

$$
d \sum_{i=1}^{l} \beta_{i} \int_{\eta_{i}}^{1}(f(t, d, 0)+e(t)) d t>0
$$

for all $|d|>M^{*}$ or

$$
d \sum_{i=1}^{l} \beta_{i} \int_{\eta_{i}}^{1}(f(t, d, 0)+e(t)) d t<0
$$

for all $|d|>M^{*}$.

$\left(L_{3}\right)$ There exist functions $a, b, c, r \in L^{1}[0,1]$ and $\theta \in[0,1)$ such that

$$
|f(t, x, y)| \leq a(t)|x|+b(t)|y|+c(t)|x|^{\theta}+r(t)
$$

or

$$
|f(t, x, y)| \leq a(t)|x|+b(t)|y|+c(t)|y|^{\theta}+r(t) .
$$

Then problem (1) and $\left(1_{1}\right)$ has at least one solution if $\|a\|_{1}+\|b\|_{1}<1 / 2$.

Theorem $\boldsymbol{L Y}_{\mathbf{2}}\left(\left[14\right.\right.$, Theorem 3.6]). Suppose $\sum_{i=1}^{l} \beta_{i}=1$ and $\sum_{i=1}^{l} \beta_{i} \eta_{i}$ $\neq 1,\left(L_{3}\right)$ holds and

$\left(L_{4}\right)$ There is $M>0$ such that for each $x \in D(L)$ if $\left|x^{\prime}(t)\right|>M$ for all $t \in[0,1]$ one has

$$
\sum_{i=1}^{l} \beta_{i} \int_{\eta_{i}}^{1}\left(f\left(t, x(t), x^{\prime}(t)\right)+e(t)\right) d t \neq 0 .
$$


$\left(L_{5}\right)$ There is $M^{*}>0$ such that

$$
d \sum_{i=1}^{l} \beta_{i} \int_{\eta_{i}}^{1}(f(t, d t, d)+e(t)) d t>0
$$

for all $|d|>M^{*}$ or

$$
d \sum_{i=1}^{l} \beta_{i} \int_{\eta_{i}}^{1}(f(t, d t, d)+e(t)) d t<0
$$

for all $|d|>M^{*}$.

Then problem (1) and $\left(1_{2}\right)$ has at least one solution if $\|a\|_{1}+\|b\|_{1}<1 / 2$.

Consider problem

$$
\left\{\begin{array}{l}
x^{\prime \prime}(t)=-\theta\left[x^{\prime}(t)\right]^{3}+p(t) x^{\prime}(t)+q(t) x(t)+r(t), \quad 0<t<1, \\
x^{\prime}(0)=x^{\prime}(1)-\sum_{i=1}^{m} \beta_{i} x^{\prime}\left(\eta_{i}\right)=0
\end{array}\right.
$$

where $\theta>0, \sum_{i=1}^{l} \beta_{i}=1$ and $\sum_{i=1}^{l} \beta_{i} \eta_{i}=1$, and problem

$$
\left\{\begin{array}{l}
x^{\prime \prime}(t)=\frac{1}{2} x^{\prime}(t)+\frac{1}{4} x(t)+r(t), \quad 0<t<1, \\
x(0)=x^{\prime}(1)+\frac{1}{2} x^{\prime}-2 \frac{3}{4} x^{\prime}=0 .
\end{array}\right.
$$

It is easy to see that problem $(*)$ and problem $(* *)$ can not be solved by Theorems $L Y_{1}$ and $L Y_{2}$ since

$$
f(t, x, y)=-\theta y^{3}+p(t) y+q(t) x+r(t)
$$

in problem $(*)$ and $f$ does not satisfy $\left(L_{3}\right)$, and

$$
f(t, x, y)=\frac{1}{2} y+\frac{1}{4} x+r(t)
$$

in problem $(* *)$ and $\|a\|_{1}+\|b\|_{1}<1 / 2$ does not hold. Furthermore, it is not easy to test the conditions $\left(L_{1}\right)$ and $\left(L_{4}\right)$ in Theorem $L Y_{1}$ and Theorem $L Y_{2}$, respectively. We also find that the solvability of problem $(1)$ and $\left(1_{1}\right)$ and problem (1) and $\left(1_{2}\right)$ were not settled when $\sum_{i=1}^{l} \beta_{i}=1$ and $\sum_{i=1}^{l} \beta_{i} \eta_{i}=1$, for example, see problem $(* *)$.

In recent paper [9], Gupta studied the solvability of the following nonresonance problem

$$
\left\{\begin{array}{l}
{\left[\phi\left(x^{\prime}(t)\right)\right]^{\prime}=f\left(t, x(t), x^{\prime}(t)\right)+e(t), \quad t \in(0,1),} \\
x(0)=0, \quad \phi\left(x^{\prime}(1)\right)=\sum_{i=1}^{m} \alpha_{i} \phi\left(x^{\prime}\left(\xi_{i}\right)\right),
\end{array}\right.
$$


where $\phi$ is an odd increasing homeomorphism from $\mathbb{R}$ on to $\mathbb{R}$ and $\sum_{i=1}^{m} \alpha_{i}$ $\neq 1$. We find that the case where $\sum_{i=}^{m} \alpha_{i}=1$ is not considered in [9]. If $\sum_{i=1}^{m} \alpha_{i} \neq 1$, Gupta proved the following theorem:

Theorem G ([9, Theorem 3.1]). Assume that there is functions $p, q, r \in$ $L^{1}[0,1]$ such that

$$
|f(t, x, y)| \leq p(t)|x|+q(t)|y|+r(t) .
$$

Then problem (2) has at least one solution if $\|p\|_{1}+\|q\|_{1}+\tau<1$, where

$$
\tau=\min \left\{\frac{\sum_{i=1}^{m-2}\left(\alpha_{i}\right)_{+}}{\sum_{i=1}^{m-2}\left(\alpha_{i}\right)_{-}+1}, \frac{\sum_{i=1}^{m-2}\left(\alpha_{i}\right)_{-}+1}{\sum_{i=1}^{m-2}\left(\alpha_{i}\right)_{+}}\right\} .
$$

In paper [5], the authors studied the following problem

$$
\begin{cases}{\left[\phi\left(x^{\prime}(t)\right)\right]^{\prime}=f\left(t, x(t), x^{\prime}(t)\right),} & t \in(0,1), \\ x^{\prime}(0)=0, & \theta\left(x^{\prime}(1)\right)=\sum_{i=1}^{m} \alpha_{i} \theta\left(x^{\prime}\left(\xi_{i}\right)\right),\end{cases}
$$

which contains the problem

$$
\begin{cases}{\left[\phi\left(x^{\prime}(t)\right)\right]^{\prime}=f\left(t, x(t), x^{\prime}(t)\right),} & t \in(0,1), \\ x^{\prime}(0)=0, \quad \phi\left(x^{\prime}(1)\right)=\sum_{i=1}^{m} \alpha_{i} \phi\left(x^{\prime}\left(\xi_{i}\right)\right) & \end{cases}
$$

as special case, where $\phi$ and $\theta$ are two odd increasing homeomorphism from $\mathbb{R}$ onto $\mathbb{R}$ with $\phi(0)=\theta(0)=0, \alpha_{i} \in \mathbb{R}$ and $\xi_{i} \in(0,1)$ for $i=1, \ldots, m$, $f$ is a continuous function. They established the existence results for problem (3) under one of the following assumptions:

$\left(G_{1}\right) 0 \leq \sum_{i=1}^{m} \alpha_{i} \leq 1$, there are non-negative functions $d_{1}(t)$ and $d_{2}(t)$ and $r(t)$ such that

$|f(t, u, v)| \leq d_{1}(t) \phi(|u|)+d_{2}(t) \phi(|v|)+r(t)$ for $t \in[0,1], u, v \in \mathbb{R}$,

and there are constants $M>0, A, B \geq 0$ and a $u_{0}>0$ such that for all $u$ with $|u|>u_{0}$, all $t \in[0,1]$ and all $v \in \mathbb{R}$ one has

$$
|f(t, u, v)| \geq M \phi(|u|)-A \phi(|v|)-B .
$$

$\left(G_{2}\right) 0 \leq \sum_{i=1}^{m} \alpha_{i} \leq 1$, for any $K>0$, there are non-negative functions $b_{1}(t)$ and $b_{2}(t)$ so that

$$
|f(t, u, v)| \leq b_{1}(t)+b_{2}(t) \phi(|v|) \quad \text { for } t \in[0,1],|u| \leq K, v \in \mathbb{R} .
$$

It is easy to see that the cases where $\sum_{i=1}^{m} \alpha_{i}<0$ or $\sum_{i=1}^{m} \alpha_{i}>1$ were not considered in [5].

For problem $\left(3^{\prime}\right)$, the authors proved the following theorem. 
Theorem GH ([5, Theorem 11]). Suppose that the following conditions are satisfied:

$\left(G_{1}\right)$ There are non-negative functions $d_{1}, d_{2}, r \in L^{1}[0,1]$ such that

$$
|f(t, u, v)| \leq d_{1}(t) \phi(|u|)+d_{2}(t) \phi(|v|)+r(t) \quad \text { for } t \in[0,1], u, v \in \mathbb{R} .
$$

$\left(G_{2}\right)$ There is $d>0$ such that for all $x \in C^{1}[0,1]$ with $|x(t)|>d$ for all $t \in[0,1]$ it holds that

$$
\int_{0}^{1} f\left(t, x(t), x^{\prime}(t)\right) d t-\sum_{i=1}^{m} \alpha_{i} \int_{0}^{\xi_{i}} f\left(t, x(t), x^{\prime}(t)\right) d t \neq 0 .
$$

$\left(G_{3}\right)$ For every $R>0$ there is $|\rho|>R$ such that $F(\rho) F(-\rho)<0$, where

$$
F(\rho)=\int_{0}^{1} f(t, \rho, 0) d t-\sum_{i=1}^{m} \alpha_{i} \int_{0}^{\xi_{i}} f(t, \rho, 0) d t .
$$

$\left(G_{4}\right)\left\|d_{2}\right\|<1$ and

$$
\lim _{z \rightarrow \infty} \sup \frac{\Gamma(z)}{z}<1
$$

where

$$
\Gamma(z)=\phi\left(\frac{\left\|d_{1}\right\|}{1-\left\|d_{2}\right\|} \phi(z)+\frac{\|r\|}{1-\left\|d_{2}\right\|}\right) .
$$

Then problem $\left(3^{\prime}\right)$ has at least one solution $x \in C^{1}[0,1]$.

To the best of our knowledge, there has been no other paper concerned with the existence of solutions of multi-point boundary value problems for higher-order differential equations with $p$-Laplacian at resonance, though there was a considerable number of papers concerned with the existence of positive solutions or solutions of second-order differential equations with $p$-Laplacian at non-resonance cases [4], [7], [8], [10], [11], [12] or concerned with the solvability of boundary value problems for higher-order differential equations without $p$-Laplacian at non-resonance cases or resonance case [1], [2], [3], [17], [18], [19], [20].

Following notations and abstract existence theorem by Mawhin [21], [22] will be used in this paper.

Let $X$ and $Y$ be Banach spaces, $L: D(L) \subset X \rightarrow Y$ be a Fredholm operator of index zero, $P: X \rightarrow X, Q: Y \rightarrow Y$ be projectors such that

$\operatorname{Im} P=\operatorname{Ker} L, \quad$ Ker $Q=\operatorname{Im} L, \quad X=\operatorname{Ker} L \oplus \operatorname{Ker} P, \quad Y=\operatorname{Im} L \oplus \operatorname{Im} Q$.

It follows that

$$
\left.L\right|_{D(L) \cap \text { Ker } P}: D(L) \cap \operatorname{Ker} P \rightarrow \operatorname{Im} L
$$

is invertible, we denote the inverse of that map by $K_{p}$. 
If $\Omega$ is an open bounded subset of $X, D(L) \cap \bar{\Omega} \neq \emptyset$, map $N: \rightarrow Y$ will be called $L$-compact on $\bar{\Omega}$ if $Q N(\bar{\Omega})$ is bounded and $K_{p}(I-Q) N: \bar{\Omega} \rightarrow X$ is compact.

Theorem M ([21], [22]). Let $L$ be a Fredholm operator of index zero and let $N$ be L-compact on $\Omega$. Assume that the following conditions are satisfied:

(i) $L x \neq \lambda N x$ for every $(x, \lambda) \in[(D(L) \backslash \operatorname{Ker} L) \cap \partial \Omega] \times(0,1)$;

(ii) $N x \notin \operatorname{Im} L$ for every $x \in \operatorname{Ker} L \cap \partial \Omega$;

(iii) $\operatorname{deg}\left(\left.\wedge Q N\right|_{\text {Ker } L}, \Omega \cap \operatorname{Ker} L, 0\right) \neq 0$, where $\wedge: Y / \operatorname{Im} L \rightarrow \operatorname{Ker} L$ is the isomorphism.

Then the equation $L x=N x$ has at least one solution in $D(L) \cap \bar{\Omega}$.

Theorem $\mathrm{M}$ is reported to be the most classical method to approach the boundary value problems at resonance case for second order or higher order differential equations. In this method, one decomposes the space as the direct sum of subspace, one of which is Ker $L$, and then to work with the corresponding projections on these spaces. For instance see papers [4], [7], [13], [14], [15], [16] for BVP of second order differential equations and [17], [18], [19], [20] for higher order differential equations and the references therein. There is no paper concerned with the solvability of multi-point BVP for higher order differential equations with $p$-Laplacian since the methods used in [4], [7], [13], [14], [15], [16], [17], [18], [19], [20] can not be copied to discuss these kinds of problems.

Motivated and inspired by papers [5], [9], [13], [14], [15], [16] and the reason mentioned above, we are concerned with the following higher-order differential equation with $p$-Laplacian

$$
\left[\phi\left(x^{(n-1)}(t)\right)\right]^{\prime}=f\left(t, x(t), x^{\prime}(t), \ldots, x^{(n-1)}(t)\right), \quad 0<t<1,
$$

subjected to one of the following multi-point boundary value conditions

$$
\begin{aligned}
& \left\{\begin{array}{l}
x^{(i)}(0)=0 \\
\phi\left(x^{(n-1)}(1)\right)-\sum_{i=1}^{l} \beta_{i} \phi\left(x^{(n-1)}\left(\eta_{i}\right)\right)=0,
\end{array}\right. \\
& \left\{\begin{array}{l}
x^{(i)}(0)=0 \\
x^{(n-1)}(0)=0, \\
\phi\left(x^{(n-1)}(1)\right)-\sum_{i=1}^{l} \beta_{i} \phi\left(x^{(n-1)}\left(\eta_{i}\right)\right)=0,
\end{array}\right.
\end{aligned}
$$

where $n \geq 2,0<\eta_{i}<1, \beta_{i} \in \mathbb{R}$ for all $i=1, \ldots, l$ and $f$ is Caratheodory functions, and $\phi$ is an odd increasing homeomorphism from $\mathbb{R}$ onto $\mathbb{R}$ with $\phi(0)=0$, whose inverse is written by $\phi^{-1}$. 
The purpose of this paper is to establish the existence results, by using a transformation, for the solutions of BVP (4)-(5) in the case $\sum_{i=1}^{l} \beta_{i}=1$ and BVP (4)-(6), respectively. Our results generalize and complement those in [5], [9], [13], [14], [15], [16]. Problem $(*)$ and problem $(* *)$ can be solved by theorems in this paper. Even when $\phi(x)=x$, we do not require the assumptions $\sum_{i=1}^{l} \beta_{i}=1$ and $\sum_{i=1}^{l} \beta_{i} \eta_{i} \neq 1$.

This paper is organized as follows. In Section 2.1, the existence results for solutions of BVP (4)-(5) are established. We will present the existence results for solutions of BVP (4)-(6) in Section 2.2. Results show us that known theorems are complemented and improved.

\section{MAIN RESUltS}

To obtain solutions of BVP (4)-(5) and BVP (4)-(6), let $x_{1}(t)=x(t)$, $x_{2}(t)=\phi\left(x^{(n-1)}(t)\right)$. Then BVP $(4)-(5)$ becomes

$$
\begin{aligned}
& \left\{\begin{array}{lr}
x_{1}^{(n-1)}(t)=\phi^{-1}\left(x_{2}(t)\right), & 0<t<1, \\
x_{2}^{\prime}(t)=f\left(t, x_{1}(t), \ldots, x_{1}^{(n-2)}(t), \phi^{-1}\left(x_{2}(t)\right)\right), & 0<t<1,
\end{array}\right. \\
& \left\{\begin{array}{lr}
x_{1}^{(i)}(0)=0, & i=0, \ldots, n-2, \\
x_{2}(1)-\sum_{i=1}^{l} \beta_{i} x_{2}\left(\eta_{i}\right)=0,
\end{array}\right.
\end{aligned}
$$

and BVP (4)-(6) becomes

$$
\begin{aligned}
& \begin{cases}x_{1}^{(n-1)}(t)=\phi^{-1}\left(x_{2}(t)\right), & 0<t<1, \\
x_{2}^{\prime}(t)=f\left(t, x_{1}(t), \ldots, x_{1}^{(n-2)}(t), \phi^{-1}\left(x_{2}(t)\right)\right), & 0<t<1,\end{cases} \\
& \begin{cases}x_{1}^{(i)}(0)=0, & i=0, \ldots, n-3, \\
x_{2}(0)=0, & \\
x_{2}(1)-\sum_{i=1}^{l} \beta_{i} x_{2}\left(\eta_{i}\right)=0 .\end{cases}
\end{aligned}
$$

It is easy to show that if $\left(x_{1}, x_{2}\right) \in C^{n-1}[0,1] \times C^{1}[0,1]$ is a solution of BVP (7) or BVP (8), then $x_{1}$ is a solution of BVP (4)-(5) or BVP (4)-(6), respectively.

Let $X=C^{n-2}[0,1] \times C^{0}[0,1]$ be endowed with the norm

$$
\begin{aligned}
\|x\| & =\left\|\left(x_{1}, x_{2}\right)^{T}\right\| \\
& =\max \left\{\max _{0 \leq t \leq 1}\left|x_{1}(t)\right|, \ldots, \max _{0 \leq t \leq 1}\left|x_{1}^{(n-2)}(t)\right|, \max _{0 \leq t \leq 1}\left|x_{2}(t)\right|,\right\}
\end{aligned}
$$


for $x=\left(x_{1}, x_{2}\right) \in X$, then $X$ is a Banach space. Let $Y=C^{0}[0,1] \times C^{0}[0,1] \times$ $\mathbb{R}^{n}$ be endowed with the norm

$$
\left\|\left(y_{1}(t), y_{2}(t), a_{0}, \ldots, a_{n-1}\right)^{T}\right\|=\max \left\{\left\|\left(y_{1}, y_{2}\right)\right\|,\left|a_{0}\right|, \ldots,\left|a_{n-1}\right|\right\}
$$

for $y=\left(y_{1}, y_{2}, a_{0}, \ldots, a_{n-1}\right) \in Y$, then $Y$ is a Banach space. Set $D\left(L_{1}\right)=$ $D\left(L_{2}\right)=C^{n-1}[0,1] \times C^{1}[0,1]$.

Define the line operator $L_{1}: D\left(L_{1}\right) \cap X \rightarrow Y$ in $D\left(L_{1}\right)$ by

$$
L_{1}\left(\begin{array}{c}
x_{1}(t) \\
x_{2}(t)
\end{array}\right)=\left(\begin{array}{c}
x_{1}^{(n-1)}(t) \\
x_{2}^{\prime}(t) \\
x_{1}(0) \\
\vdots \\
x_{1}^{(n-2)}(0) \\
x_{2}(1)-\sum_{i=1}^{l} \beta_{i} x_{2}\left(\eta_{i}\right)
\end{array}\right) \text { for }\left(x_{1}, x_{2}\right) \in D\left(L_{1}\right)
$$

the linear operator $L_{2}: D\left(L_{2}\right) \cap X \rightarrow Y$ in $D\left(L_{2}\right)$ by

$$
L_{2}\left(\begin{array}{c}
x_{1}(t) \\
x_{2}(t)
\end{array}\right)=\left(\begin{array}{c}
x_{1}^{(n-1)}(t) \\
x_{2}^{\prime}(t) \\
x_{1}(0) \\
\vdots \\
x_{1}^{(n-3)}(0) \\
x_{2}(0) \\
x_{2}(1)-\sum_{i=1}^{l} \beta_{i} x_{2}\left(\eta_{i}\right)
\end{array}\right) \text { for }\left(x_{1}, x_{2}\right) \in D\left(L_{2}\right)
$$

Define the nonlinear operator $N: X \rightarrow Y$ by

$$
N\left(\begin{array}{c}
x_{1}(t) \\
x_{2}(t)
\end{array}\right)=\left(\begin{array}{c}
\phi^{-1}\left(x_{2}(t)\right) \\
f\left(t, x_{1}(t), \ldots, x_{1}^{(n-2)}(t), \phi^{-1}\left(x_{2}(t)\right)\right) \\
0 \\
\vdots \\
0 \\
0
\end{array}\right) \text { for }\left(x_{1}, x_{2}\right)^{T} \in X .
$$

It is easy to see that $\left(x_{1}, x_{2}\right) \in D\left(L_{1}\right)$ is a solution of (7) if and only if $\left(x_{1}, x_{2}\right)$ is a solution of operator equation $L\left(x_{1}, x_{2}\right)^{T}=N\left(x_{1}, x_{2}\right)^{T}$ in $D\left(L_{1}\right)$. $\left(x_{1}, x_{2}\right) \in D\left(L_{2}\right)$ is a solution of $(8)$ if and only if $\left(x_{1}, x_{2}\right)$ is a solution of operator equation $L\left(x_{1}, x_{2}\right)^{T}=N\left(x_{1}, x_{2}\right)^{T}$ in $D\left(L_{2}\right)$. 


\subsection{Existence results for BVP (4)-(5).}

In this subsection, the existence results for BVP (4)-(5) will be established. Since the case when $\sum_{i=1}^{l} \beta_{i} \neq 1$ was considered in [9], we will study the case when $\sum_{i=1}^{l} \beta_{i}=1$. The corresponding linear problem of BVP (7) is

$$
\begin{cases}x_{1}^{(n-1)}(t)=0, & 0<t<1 \\ x_{2}^{\prime}(t)=0, & 0<t<1 \\ x_{1}^{(i)}(0)=0 & \text { for } i=0,1, \ldots, n-2 \\ x_{2}(1)-\sum_{i=1}^{l} \beta_{i} x_{2}\left(\eta_{i}\right)=0 . & \end{cases}
$$

Lemma 2.1. The following results hold.

(i) Ker $L_{1}=\left\{\left(x_{1}(t), x_{2}(t)\right)^{T}=(0, c)^{T}, t \in[0,1], c \in \mathbb{R}\right\}$.

(ii) $\operatorname{Im} L_{1}=\left\{\left(y_{1}, y_{2}, a_{0}, \ldots, a_{n-1}\right) \in Y\right.$,

$$
\left.\int_{0}^{1} y_{2}(s) d s-\sum_{i=1}^{l} \beta_{i} \int_{0}^{\eta_{i}} y_{2}(s) d s=a_{n-1}\right\} .
$$

(iii) $L_{1}$ is a Fredholm operator of index zero;

(iv) There exists a positive integer $k$ so that $1-\sum_{i=1}^{l} \beta_{i} \eta^{k} \neq 0$.

(v) There are projectors $P: X \rightarrow X$ and $Q: Y \rightarrow Y$ such that Ker $L_{1}=$ $\operatorname{Im} P$, Ker $Q=\operatorname{Im} L_{1}, X=\operatorname{Ker} L_{1} \oplus \operatorname{Im} P$ and $Y=\operatorname{Im} L_{1} \oplus \operatorname{Ker} Q$. Furthermore, let $\Omega \subset X$ be an open bounded subset with $\bar{\Omega} \cap D\left(L_{1}\right) \neq \emptyset$, then $N$ is $L_{1}$-compact on $\bar{\Omega}$.

Proof. The proofs of (i)-(v) are similar to those of lemmas in [13], [14], [15], [16] and are omitted. We write down the projectors $P: X \rightarrow X$ and $Q: Y \rightarrow Y$ and the generalized inverse $K_{p}: \operatorname{Im} L \rightarrow D(L) \cap \operatorname{Im} P$. Let $x=\left(x_{1}, x_{2}\right) \in X$ and $y=\left(y_{1}, y_{2}, a_{1}, \ldots, a_{n}\right) \in Y$, we have

$$
\begin{aligned}
P x(t) & =\left(0, x_{2}(0)\right), \\
Q y(t) & =\left(0, \frac{\int_{0}^{1} y_{2}(s) d s-\sum_{i=1}^{l} \beta_{i} \int_{0}^{\eta_{i}} y_{2}(s) d s-a_{n-1}}{\Delta} t^{k-1}, 0, \ldots, 0\right), \\
K_{p} y(t) & =\left(\int_{0}^{t} \frac{(t-s)^{n-2}}{(n-2) !} y_{1}(s) d s, \int_{0}^{t} y_{2}(s) d s\right),
\end{aligned}
$$


where

$$
\Delta=\frac{1}{k}\left(1-\sum_{i=1}^{l} \eta_{i}^{k}\right) .
$$

The inverse isomorphism of $\wedge: \operatorname{Ker} L_{1} \rightarrow Y / \operatorname{Im} L_{1}$ is $\wedge^{-1}: Y / \operatorname{Im} L_{1} \rightarrow$ Ker $L_{1}$ given by $\wedge^{-1}\left(0, c t^{k-1}, 0, \ldots, 0\right)=(0, c)$. The proof is complete.

Now suppose the following:

$\left(A_{1}\right)$ There exist continuous function $e(t)$ and nonnegative continuous functions $g_{i}(t, x)(i=0,1, \ldots, n-1)$ such that $f$ satisfies

$$
\left|f\left(t, x_{0}, x_{1}, \ldots, x_{n-1}\right)\right| \leq e(t)+\sum_{i=0}^{n-1} g_{i}\left(t, x_{i}\right),
$$

for all $t \in[0,1]$ and $\left(x_{0}, x_{1}, \ldots, x_{n-1}\right) \in \mathbb{R}^{n}$ and

$$
\lim _{|x| \rightarrow \infty} \sup _{t \in[0,1]} \frac{\left|g_{i}(t, x)\right|}{\phi(|x|)}=r_{i}, \quad \text { for } i=0,1, \ldots, n-1
$$

with $\infty>r_{i} \geq 0$ for $i=0,1, \ldots, n-1$;

$\left(A_{2}\right)$ There exists $i_{0} \in\{1, \ldots, l\}$ such that $\beta_{i} \geq 0$ for $i=1, \ldots, i_{0}$ and $\beta_{i}<0$ for all $i=i_{0}+1, \ldots, l$.

$\left(A_{3}\right)$ There exists a constant $M>0$ such that

$$
f\left(t, x_{0}, \ldots, x_{n-2}, \phi^{-1}\left(x_{n-1}\right)\right)>0
$$

for all $x_{i} \geq 0(i=0, \ldots, n-2)$ and $\phi^{-1}\left(x_{n-1}\right)>M$ or

$$
f\left(t, x_{0}, \ldots, x_{n-2}, \phi^{-1}\left(x_{n-1}\right)\right)<0
$$

for all $x_{i} \leq 0(i=0, \ldots, n-2)$ and $\phi^{-1}\left(x_{n-1}\right)<-M$.

Theorem 2.1. Assume $\left(A_{1}\right),\left(A_{2}\right)$ and $\left(A_{3}\right)$ hold. Then BVP $(4)-(5)$ has at least one solution provided

$$
\sum_{i=1}^{n-1} r_{i}<1
$$

Proof. We note that if $\left(x_{1}, x_{2}\right)$ is a solution of $(7)$, then $x_{1}$ is a solution of BVP (4)-(5). It suffices to obtain a solution $\left(x_{1}, x_{2}\right)$ of BVP $(7)$. To apply Theorem M, we will do the following steps. 
Step 1. Let $\Omega_{1}=\left\{x \in D\left(L_{1}\right) \backslash \operatorname{Ker} L_{1}, L_{1} x=\lambda N x\right.$ for some $\left.\lambda \in(0,1)\right\}$. We prove that $\Omega_{1}$ is bounded. For $x \in \Omega_{1}$, we get

$$
\begin{aligned}
& \begin{cases}x_{1}^{(n-1)}(t)=\lambda \phi^{-1}\left(x_{2}(t)\right), & 0<t<t<1, \\
x_{2}^{\prime}(t)=\lambda f\left(t, x_{1}(t), \ldots, x_{1}^{(n-2)}(t), \phi^{-1}\left(x_{2}(t)\right)\right), & 0<t<1,\end{cases} \\
& \begin{cases}x_{1}^{(i)}(0)=0, & i=0, \ldots, n-2, \\
x_{2}(1)-\sum_{i=1}^{l} \beta_{i} x_{2}\left(\eta_{i}\right)=0 . & \end{cases}
\end{aligned}
$$

If $\phi^{-1}\left(x_{2}(t)\right)>M$ for all $t \in[0,1]$, then

$$
x_{1}^{(i)}(t)=\lambda \int_{0}^{t} \frac{(t-s)^{n-i-2}}{(n-i-2) !} \phi^{-1}\left(x_{2}(s)\right) d s \geq 0, \quad i=0, \ldots, n-2 .
$$

Thus from $\left(A_{3}\right)$ we get

$$
f\left(t, x_{1}(t), \ldots, x_{1}^{(n-2)}(t), \phi^{-1}\left(x_{2}(t)\right)\right)>0 \quad \text { for all } t \in[0,1] .
$$

Hence $x_{2}(t)$ is increasing on $[0,1]$. So we get from $\left(A_{2}\right)$ that

$$
x_{2}(1)=\sum_{i=1}^{l} \beta_{i} x_{2}\left(\eta_{i}\right)<\sum_{i=1}^{l} \beta_{i} x_{2}\left(\eta_{i_{0}}\right)=x_{2}\left(\eta_{i_{0}}\right)<x_{2}(1),
$$

a contradiction. Similar discussion shows us that $\phi^{-1}\left(x_{2}(t)\right)<-M$ induces a contradiction. Then there is $t_{0} \in[0,1]$ so that $\phi^{-1}\left(\left|x_{2}\left(t_{0}\right)\right|\right) \leq M$. It follows from (10) that

$$
x_{2}^{\prime}(t)=\lambda f\left(t, x_{1}(t), \ldots, x_{1}^{(n-2)}(t), \phi^{-1}\left(x_{2}(t)\right)\right), \quad 0<t<1 .
$$

Integrating it from $t_{0}$ to $t$, we get from $\left(A_{1}\right)$ that

$$
\begin{aligned}
\left|x_{2}(t)\right| & =\left|x_{2}\left(t_{0}\right)+\lambda \int_{t_{0}}^{t} f\left(s, x_{1}(s), \ldots, x_{1}^{(n-2)}(s), \phi^{-1}\left(x_{2}(s)\right)\right) d s\right| \\
& \leq \phi(M)+\int_{0}^{1}\left|f\left(s, x_{1}(s), \ldots, x_{1}^{(n-2)}(s), \phi^{-1}\left(x_{2}(s)\right)\right)\right| d s \\
& \leq \phi(M)+\int_{0}^{1}|e(s)| d s+\sum_{i=0}^{n-2} \int_{0}^{1}\left|g_{i}\left(s, x_{1}^{(i)}(s)\right)\right| d s \\
& +\int_{0}^{1}\left|g_{n-1}\left(s, \phi^{-1}\left(x_{2}(s)\right)\right)\right| d s .
\end{aligned}
$$

It is easy to get

$$
\left\|x_{1}^{(i)}\right\| \leq\left\|x^{(n-1)}\right\| \leq \phi^{-1}\left(\left\|x_{2}\right\|\right) \quad \text { for } i=0, \ldots, n-1 .
$$


It follows from (9) that there is $\varepsilon>0$ so that

$$
\sum_{i=0}^{n-1}\left(r_{i}+\varepsilon\right)<1 .
$$

For this $\varepsilon$, we get $\delta>0$ so that

$$
\left|g_{i}(t, x)\right| \leq\left(r_{i}+\varepsilon\right) \phi(|x|) \quad \text { for all } t \in[0,1],|x| \geq \delta, i=0, \ldots, n-1 .
$$

Let, for $i=0,1, \ldots, n-2$,

$$
\begin{gathered}
\Delta_{1, i}=\left\{t \in[0,1],\left|x^{(i)}(t)\right| \leq \delta\right\}, \quad \Delta_{2, i}=\left\{t \in[0,1],\left|x^{(i)}(t)\right|>\delta\right\}, \\
g_{\delta, i}=\max _{t \in[0,1],|x| \leq \delta}\left|g_{i}(t, x)\right|,
\end{gathered}
$$

and

$$
\begin{aligned}
\Delta_{1, n-1} & =\left\{t \in[0,1], \phi^{-1}\left(\left|x_{2}(t)\right|\right) \leq \delta\right\}, \\
\Delta_{2, n-1} & =\left\{t \in[0,1], \phi^{-1}\left(\left|x^{(i)}(t)\right|\right)>\delta\right\}, \\
g_{\delta, n-1} & =\max _{t \in[0,1], \phi^{-1}(|x|) \leq \delta}\left|g_{i}\left(t, \phi^{-1}(x)\right)\right| .
\end{aligned}
$$

So

$$
\begin{aligned}
\left|x_{2}(t)\right| \leq & \phi(M)+\int_{0}^{1}|e(s)| d s+\sum_{i=0}^{n-2} \int_{\Delta_{1, i}}\left|g_{i}\left(s, x_{1}^{(i)}(s)\right)\right| d s \\
& +\sum_{i=0}^{n-2} \int_{\Delta_{2, i}}\left|g_{i}\left(s, x_{1}^{(i)}(s)\right)\right| d s \\
& +\int_{\Delta_{1, n-1}}\left|g_{n-1}\left(s, \phi^{-1}\left(x_{2}(s)\right)\right)\right| d s \\
& +\int_{\Delta_{1, n-1}}\left|g_{n-1}\left(s, \phi^{-1}\left(x_{2}(s)\right)\right)\right| d s \\
\leq & \phi(M)+\int_{0}^{1}|e(s)| d s+\sum_{i=0}^{n-2} g_{\delta, i}+\sum_{i=0}^{n-2}\left(r_{i}+\varepsilon\right) \int_{0}^{1} \phi\left(\left|x^{(i)}(s)\right|\right) d s \\
& +g_{\delta, n-1}+\left(r_{n-1}+\varepsilon\right) \int_{0}^{1} \phi\left(\phi^{-1}\left(\left|x_{2}(s)\right|\right)\right) d s \\
\leq & \phi(M)+\int_{0}^{1}|e(s)| d s+\sum_{i=0}^{n-1} g_{\delta, i} \\
& +\sum_{i=0}^{n-2}\left(r_{i}+\varepsilon\right) \phi\left(\phi^{-1}\left(\left\|x_{2}\right\|_{\infty}\right)\right)+\left(r_{n-1}+\varepsilon\right)\left\|x_{2}\right\|_{\infty}
\end{aligned}
$$




$$
\begin{aligned}
\leq & \phi(M)+\int_{0}^{1}|e(s)| d s+\sum_{i=0}^{n-1} g_{\delta, i} \\
& +\sum_{i=0}^{n-2}\left(r_{i}+\varepsilon\right)\left\|x_{2}\right\|_{\infty}+\left(r_{n-1}+\varepsilon\right)\left\|x_{2}\right\|_{\infty} .
\end{aligned}
$$

Hence

$\left\|x_{2}\right\|_{\infty} \leq \phi(M)+\int_{0}^{1}|e(s)| d s+\sum_{i=0}^{n-1} g_{\delta, i}+\sum_{i=0}^{n-2}\left(r_{i}+\varepsilon\right)\left\|x_{2}\right\|_{\infty}+\left(r_{n-1}+\varepsilon\right)\left\|x_{2}\right\|_{\infty}$.

We get

$$
\left(1-\sum_{i=0}^{n-1}\left(r_{i}+\varepsilon\right)\right)\left\|x_{2}(s)\right\|_{\infty} \leq \phi(M)+\int_{0}^{1}|e(s)| d s+\sum_{i=0}^{n-1} g_{\delta, i} .
$$

By the definition of $\varepsilon$, we get there is constant $M_{1}>0$ so that $\left\|x_{2}\right\|_{\infty} \leq M_{1}$. Now, we see that

$$
\left\|x_{1}^{(i)}\right\|_{\infty} \leq \phi^{-1}\left(\left\|x_{2}\right\|_{\infty}\right) \leq \phi^{-1}\left(M_{1}\right) \quad \text { for } i=1, \ldots, n-2 .
$$

This implies that there is $B>0$ so that $\left\|\left(x_{1}, x_{2}\right)\right\| \leq B$. Hence $\Omega_{1}$ is bounded. This completes the Step 1.

Step 2. Let $\Omega_{2}=\{x \in \operatorname{Ker} L: N x \in \operatorname{Im} L\}$. For $x \in \Omega_{2}$, then $x(t)=(0, a)$ for some $a \in \mathbb{R}$. $N x=\left(\phi^{-1}(a), f\left(t, 0, \ldots, 0, \phi^{-1}(a)\right), 0, \ldots, 0\right) \in \operatorname{Im} L$ implies that there are functions $u_{1}, u_{2}$ so that

$$
\begin{aligned}
& \begin{cases}u_{1}^{(n-1)}(t)=\phi^{-1}(a), & 0<t<1, \\
u_{2}^{\prime}(t)=f\left(t, 0, \ldots, 0, \phi^{-1}(a)\right), & 0<t<1,\end{cases} \\
& \begin{cases}u_{1}^{(i)}(0)=0, & i=0, \ldots, n-2, \\
u_{2}(1)-\sum_{i=1}^{l} \beta_{i} u_{2}\left(\eta_{i}\right)=0, & \end{cases}
\end{aligned}
$$

Case 1. If $\phi^{-1}(a)>M$, we know from $\left(A_{3}\right)$ that $x_{2}^{\prime}(t)=$ $f\left(t, 0, \ldots, 0, \phi^{-1}(a)\right)>0$, then $x_{2}$ is increasing on $[0,1]$. It follows that

$$
u_{2}(1)=\sum_{i=1}^{l} \beta_{i} u_{2}\left(\eta_{i}\right)<\sum_{i=1}^{l} \beta_{i} u_{2}\left(\eta_{i_{0}}\right)=u_{2}\left(\eta_{i_{0}}\right)<u_{2}(1),
$$

a contradiction.

Case 2. If $\left.\phi^{-1}\right)(a)<-M$, similar argument induces a contradiction. It follows from above discussion that $\Omega_{2}$ is bounded.

Step 3. Let

$$
\Omega_{3}=\{x \in \operatorname{Ker} L: \lambda \operatorname{sgn}(\Delta) \wedge x+(1-\lambda) Q N x=0, \lambda \in[0,1]\},
$$


where $\wedge$ is the isomorphism given in the proof of Lemma 2.1. We will prove that $\Omega_{3}$ is bounded. For $x \in \Omega_{3}$, then $x(t)=(0, a)$. It follows from the definition of $\wedge$ and

$Q N(0, a)$

$=\left(0, \frac{\int_{0}^{1} f\left(t, 0, \ldots, 0, \phi^{-1}(a)\right) d t-\sum_{i=1}^{l} \beta_{i} \int_{0}^{\eta_{i}} f\left(t, 0, \ldots, 0, \phi^{-1}(a)\right) d t}{\Delta} t^{k-1}\right.$,

$0, \ldots, 0)$

that

$$
\begin{aligned}
\operatorname{sgn}(\Delta) \Delta \lambda a= & -(1-\lambda)\left(\int_{0}^{1} f\left(t, 0, \ldots, 0, \phi^{-1}(a)\right) d t\right. \\
& \left.-\sum_{i=1}^{l} \beta_{i} \int_{0}^{\eta_{i}} f\left(t, 0, \ldots, 0, \phi^{-1}(a)\right) d t\right) \\
= & -(1-\lambda) \sum_{i=1}^{l} \beta_{i} \int_{\eta_{i}}^{1} f\left(t, 0, \ldots, 0, \phi^{-1}(a)\right) d t .
\end{aligned}
$$

This implies

$$
\operatorname{sgn}(\Delta) \Delta \lambda a^{2}=-(1-\lambda) \sum_{i=1}^{l} \beta_{i} \int_{\eta_{i}}^{1} a f\left(t, 0, \ldots, 0, \phi^{-1}(a)\right) d t .
$$

If $\lambda=1$, then $a=0$.

If $\lambda \in[0,1)$ and $\phi^{-1}(a)>M$, then $f\left(t, 0, \ldots, 0, \phi^{-1}(a)\right)>0$. Hence

$$
\begin{aligned}
\operatorname{sgn}(\Delta) \Delta \lambda a & =-(1-\lambda) \sum_{i=1}^{l} \beta_{i} \int_{\eta_{i}}^{1} a f\left(t, 0, \ldots, 0, \phi^{-1}(a)\right) d t \\
& \leq-(1-\lambda) \sum_{i=1}^{l} \beta_{i} \int_{\eta_{i_{0}}}^{1} a f\left(t, 0, \ldots, 0, \phi^{-1}(a)\right) d t \\
& =-(1-\lambda) \int_{\eta_{i_{0}}}^{1} a f\left(t, 0, \ldots, 0, \phi^{-1}(a)\right) d t<0,
\end{aligned}
$$

a contradiction.

If $\lambda \in[0,1)$ and $\phi^{-1}(a)<-M$, then $\operatorname{sgn}(\Delta) \Delta a^{2}<0$, a contradiction. From above argument, we see that $\Omega_{3}$ is bounded.

In the following, we shall show that all conditions of Theorem GM are satisfied. Set $\Omega$ be a open bounded subset containing 0 of $X$ such that $\Omega \supset \bigcup_{i=1}^{3} \bar{\Omega}_{i}$. By Lemma 2.1, $L_{1}$ is a Fredholm operator of index zero and $N$ is $L_{1}$-compact on $\bar{\Omega}$. By the definition of $\Omega$, we have $\Omega \supset \bar{\Omega}_{1}$ and $\Omega \supset \bar{\Omega}_{2}$, 
thus $L_{1} x \neq \lambda N x$ for $x \in\left(D\left(L_{1}\right) \backslash \operatorname{Ker} L_{1}\right) \cap \partial \Omega$ and $\lambda \in(0,1) ; N x \notin \operatorname{Im} L_{1}$ for $x \in$ Ker $L_{1} \cap \partial \Omega$.

Step 4. We prove $\operatorname{deg}\left(\left.Q N\right|_{\text {Ker } L_{1}}, \Omega \cap\right.$ Ker $\left.L_{1}, 0\right) \neq 0$. In fact, let $H(x, \lambda)=$ $\pm \lambda \operatorname{sgn}(\Delta) \wedge x+(1-\lambda) Q N x$. According the definition of $\Omega$, we know $\Omega \supset \bar{\Omega}_{3}$, thus $H(x, \lambda) \neq 0$ for $x \in \partial \Omega \cap \operatorname{Ker} L_{1}$, thus by homotopy property of degree,

$$
\begin{aligned}
& \operatorname{deg}\left(Q N \mid \operatorname{Ker} L_{1}, \Omega \cap \operatorname{Ker} L_{1}, 0\right)=\operatorname{deg}\left(H(\cdot, 0), \Omega \cap \operatorname{Ker} L_{1}, 0\right) \\
& =\operatorname{deg}\left(H(\cdot, 1), \Omega \cap \operatorname{Ker} L_{1}, 0\right)=\operatorname{deg}\left( \pm \wedge, \Omega \cap \operatorname{Ker} L_{1}, 0\right) \neq 0 .
\end{aligned}
$$

Thus by Theorem M, $L_{1} x=N x$ has at least one solution $\left(x_{1}, x_{2}\right)$ in $D\left(L_{1}\right) \cap$ $\bar{\Omega}$, then $x_{1}$ is a solution of BVP (4)-(5). The proof is completed.

Similarly to the proof of Theorem 2.1, we can prove the following theorem:

Theorem 2.1'. Suppose $\sum_{i=1}^{l} \beta_{i} \neq 1$. Assume $\left(A_{1}\right)$ holds. Then BVP (4)-(5) has at least one solution provided (9) holds.

\subsection{Existence results for BVP (4)-(6).}

In this subsection, we establish the existence results for BVP (4)-(6). We do not require any restriction on $\beta_{i}$. The corresponding linear problem of BVP (8) is

$$
\begin{cases}x_{1}^{(n-1)}(t)=0, & 0<t<1 \\ x_{2}^{\prime}(t)=0, & 0<t<1 \\ x_{1}^{(i)}(0)=0 & \text { for } i=0,1, \ldots, n-3 \\ x_{2}(0)=0, & \\ x_{2}(1)-\sum_{i=1}^{l} \beta_{i} x_{2}\left(\eta_{i}\right)=0 . & \end{cases}
$$

Lemma 2.2. The following results hold.

(i) Ker $L_{2}=\left\{\left(x_{1}(t), x_{2}(t)\right)^{T}=\left(a t^{n-2}, 0\right)^{T}, t \in[0,1], a \in \mathbb{R}\right\}$.

(ii) $\operatorname{Im} L_{2}=\left\{\left(y_{1}, y_{2}, a_{0}, \ldots, a_{n-1}\right) \in Y\right.$,

$$
\left.\int_{0}^{1} y_{2}(s) d s-\sum_{i=1}^{l} \beta_{i} \int_{0}^{\eta_{i}} y_{2}(s) d s=a_{n-1}\right\} .
$$

(iii) $L_{2}$ is a Fredholm operator of index zero;

(iv) There exists a positive integer $k$ so that $1-\sum_{i=1}^{l} \beta_{i} \eta^{k} \neq 0$. 
(v) There are projectors $P: X \rightarrow X$ and $Q: Y \rightarrow Y$ such that $\operatorname{Ker} L_{2}=$ $\operatorname{Im} P$, Ker $Q=\operatorname{Im} L_{2}, X=\operatorname{Ker} L_{2} \oplus \operatorname{Im} P$ and $Y=\operatorname{Im} L_{2} \oplus \operatorname{Ker} Q$. Furthermore, let $\Omega \subset X$ be an open bounded subset with $\bar{\Omega} \cap D\left(L_{2}\right) \neq \emptyset$, then $N$ is $L_{2}$-compact on $\bar{\Omega}$.

Proof. The proofs of (i)-(v) are similar to those of Lemmas in [13], [14], [15], [16] and are omitted. We write down the projectors $P: X \rightarrow X$ and $Q: Y \rightarrow Y$ and the generalized inverse $K_{p}: \operatorname{Im} L \rightarrow D\left(L_{2}\right) \cap \operatorname{Im} P$. Let $x=\left(x_{1}, x_{2}\right) \in X$ and $y=\left(y_{1}, y_{2}, a_{1}, \ldots, a_{n}\right) \in Y$, we have

$$
\begin{aligned}
& P x(t)=\left(\frac{x^{(n-2)}(0)}{(n-2) !} t^{n-2}, 0\right), \\
& Q y(t)=\left(0, \frac{\int_{0}^{1} y_{2}(s) d s-\sum_{i=1}^{l} \beta_{i} \int_{0}^{\eta_{i}} y_{2}(s) d s-a_{n-1}}{1 / k\left(1-\sum_{i=1}^{l} \beta_{i} \eta_{i}^{k}\right)} t^{k-1}, 0, \ldots, 0\right), \\
& K_{p} y(t)=\left(\int_{0}^{t} \frac{(t-s)^{n-2}}{(n-2) !} y_{1}(s) d s, \int_{0}^{t} y_{2}(s) d s\right) .
\end{aligned}
$$

The inverse isomorphism of $\wedge: \operatorname{Ker} L_{2} \rightarrow Y / \operatorname{Im} L_{2}$ is $\wedge^{-1}: Y / \operatorname{Im} L_{2} \rightarrow$ Ker $L_{2}$ given by

$$
\wedge^{-1}\left(0, a t^{k-1}, 0, \ldots, 0\right)=\left(a t^{n-2}, 0\right) .
$$

The proof is complete.

The following assumptions are used in Theorem 2.2.

$\left(A_{4}\right)$ There exist continuous function $h\left(t, x_{0}, x_{1}, \ldots, x_{n-1}\right), e(t)$ and nonnegative continuous functions $g_{i}(t, x)(i=0,1, \ldots, n-1)$ such that $f$ satisfies

$f\left(t, x_{0}, x_{1}, \ldots, x_{n-1}\right)=e(t)+h\left(t, x_{0}, x_{1}, \ldots, x_{n-1}\right)+\sum_{i=0}^{n-1} g_{i}\left(t, x_{i}\right)$,

and also that $h$ satisfies

$$
\phi\left(x_{n-1}\right) h\left(t, x_{0}, x_{1}, \ldots, x_{n-1}\right) \leq 0
$$

for all $t \in[0,1],\left(x_{0}, x_{1}, \ldots, x_{n-1}\right) \in \mathbb{R}^{n}$ and $g_{i}(t, x)$ satisfies

$$
\limsup _{x \rightarrow+\infty, t \in[0,1]} \frac{\left|g_{i}(t, x)\right|}{\phi(|x|)}=r_{i} \in[0,+\infty) \quad \text { for } i=0, \ldots, n-1 .
$$


$\left(A_{5}\right)$ There exists $M>0$ such that for all $x \in C^{n-1}[0,1]$ with $\left|x^{(n-2)}(t)\right|>$ $M$ for all $t \in[0,1]$ and for each $\lambda \in(0,1)$ it holds that

$$
\begin{aligned}
& \int_{0}^{1} f\left(t, x(t), \ldots, x^{(n-2)}(t), \frac{1}{\lambda} x^{(n-1)}(t)\right) d t \\
& -\sum_{i=1}^{m} \alpha_{i} \int_{0}^{\eta_{i}} f\left(t, x(t), \ldots, x^{(n-2)}(t), \frac{1}{\lambda} x^{(n-1)}(t)\right) d t \neq 0 .
\end{aligned}
$$

$\left(A_{6}\right) \phi$ satisfies that there is a constant $\mu>0$ such that $\phi(x+y) \leq$ $\mu(\phi(x)+\phi(y))$ for $x \geq 0, y \geq 0$. For $p$-Laplacian operator $\phi_{p}(x)=$ $|x|^{p-2} x$ for $x \neq 0$ and $\phi(0)=0$ with $p>1$, since $(x+y)^{\alpha} \leq C_{\alpha}\left(x^{\alpha}+y^{\alpha}\right)$, $x \geq 0, y \geq 0$, where

$$
C_{\alpha}= \begin{cases}1, & \alpha=1, \\ 2^{\alpha-1}, & \alpha>1\end{cases}
$$

it is easy to see that $\phi_{p}$ satisfies $\left(A_{6}\right)$.

$\left(A_{7}\right)$ There exists a constant $M^{*}>0$ such that

$$
\begin{aligned}
& a\left[\int_{0}^{1} f\left(t, a t^{n-2}, a(n-2) t^{n-3}, \ldots, a(n-2) !, 0\right) d t\right. \\
& \left.-\sum_{i=1}^{l} \beta_{i} \int_{0}^{\eta_{i}} f\left(t, a t^{n-2}, a(n-2) t^{n-3}, \ldots, a(n-2) !, 0\right) d t\right]>0
\end{aligned}
$$

for all $|a|>M^{*}$ or

$$
\begin{aligned}
& a\left[\int_{0}^{1} f\left(t, a t^{n-2}, a(n-2) t^{n-3}, \ldots, a(n-2) !, 0\right) d t\right. \\
& \left.-\sum_{i=1}^{l} \beta_{i} \int_{0}^{\eta_{i}} f\left(t, a t^{n-2}, a(n-2) t^{n-3}, \ldots, a(n-2) !, 0\right) d t\right]<0
\end{aligned}
$$

for all $|a|>M^{*}$.

Theorem 2.2. Assume $\left(A_{2}\right),\left(A_{4}\right),\left(A_{5}\right),\left(A_{6}\right)$, and $\left(A_{7}\right)$ hold. Then $B V P$ (4)-(6) has at least one solution provided

$$
\mu \sum_{i=0}^{n-2} r_{i}+r_{n-1}<\frac{1}{2}
$$

Proof. Since $\left(x_{1}, x_{2}\right)$ is a solution of (8) implies that $x_{1}$ is a solution of BVP (4)-(6). It suffices to obtain a solution of BVP (8). To apply Theorem M, we will do the following steps. 
Step 1. Let $\Omega_{1}=\left\{x \in D\left(L_{2}\right) \backslash \operatorname{Ker} L_{2}, L_{2} x=\lambda N x\right.$ for some $\left.\lambda \in(0,1)\right\}$. We prove that $\Omega_{1}$ is bounded. For $x \in \Omega_{1}$, we get

$$
\begin{aligned}
& \begin{cases}x_{1}^{(n-1)}(t)=\lambda \phi^{-1}\left(x_{2}(t)\right), & 0<t<t<1, \\
x_{2}^{\prime}(t)=\lambda f\left(t, x_{1}(t), \ldots, x_{1}^{(n-2)}(t), \phi^{-1}\left(x_{2}(t)\right)\right), & 0<t<1,\end{cases} \\
& \begin{cases}x_{1}^{(i)}(0)=0, & i=0, \ldots, n-3, \\
x_{2}(0)=0, & \\
x_{2}(1)-\sum_{i=1}^{l} \beta_{i} x_{2}\left(\eta_{i}\right)=0 . & \end{cases}
\end{aligned}
$$

Multiplying both sides of the equation

$$
x_{2}^{\prime}(t)=\lambda f\left(t, x_{1}(t), \ldots, x_{1}^{(n-2)}(t), \phi^{-1}\left(x_{2}(t)\right)\right), \quad 0<t<1
$$

by $x_{2}(t)$ and integrating it from 0 to $t$, we get, using $\left(A_{4}\right)$, that

$$
\begin{aligned}
\frac{1}{2}\left(x_{2}(t)\right)^{2}= & \frac{1}{2}\left(x_{2}(t)\right)^{2}-\frac{1}{2}\left(x_{2}(0)\right)^{2} \\
= & \lambda \int_{0}^{t} f\left(s, x_{1}(s), x_{1}^{\prime}(s), \ldots, x_{1}^{(n-2)}(s), \phi^{-1}\left(x_{2}(s)\right)\right) x_{2}(s) d s \\
= & \lambda \int_{0}^{t} h\left(s, x_{1}(s), x_{1}^{\prime}(s), \ldots, x_{1}^{(n-2)}(s), \phi^{-1}\left(x_{2}(s)\right)\right) x_{2}(s) d s \\
& +\lambda \sum_{i=0}^{n-2} \int_{0}^{t} g_{i}\left(s, x^{(i)}(s)\right) x_{2}(s) d s \\
& +\lambda \int_{0}^{t} g_{n-1}\left(s, \phi^{-1}\left(x_{2}(s)\right)\right) x_{2}(s) d s \\
& +\lambda \int_{0}^{t} e(s) x_{2}(s) d s \\
\leq & \sum_{i=0}^{n-2} \int_{0}^{1}\left|g_{i}\left(s, x^{(i)}(s)\right)\right|\left|x_{2}(s)\right| d s \\
& +\int_{0}^{1}\left|g_{n-1}\left(s, \phi^{-1}\left(x_{2}(s)\right)\right)\right|\left|x_{2}(s)\right| d s \\
& +\int_{0}^{1}|e(s)|\left|x_{2}(s)\right| d s .
\end{aligned}
$$

Let $\varepsilon>0$ satisfy that

$$
\frac{1}{2}>\mu \sum_{i=0}^{n-2}\left(r_{i}+\varepsilon\right)+\left(r_{n-1}+\varepsilon\right) .
$$


For such a $\varepsilon>0$, we find from $\left(A_{4}\right)$ that there is a constant $\delta>0$ such that for every $i=0,1, \ldots, n-1$,

$$
\left|g_{i}(t, x)\right|<\left(r_{i}+\varepsilon\right) \phi(|x|) \quad \text { uniformly for } t \in[0,1] \text { and }|x|>\delta \text {. }
$$

Let, for $i=0,1, \ldots, n-2$,

$$
\begin{gathered}
\Delta_{1, i}=\left\{t \in[0,1],\left|x^{(i)}(t)\right| \leq \delta\right\}, \quad \Delta_{2, i}=\left\{t \in[0,1],\left|x^{(i)}(t)\right|>\delta\right\}, \\
g_{\delta, i}=\max _{t \in[0,1],|x| \leq \delta}\left|g_{i}(t, x)\right|,
\end{gathered}
$$

and

$$
\begin{aligned}
& \Delta_{1, n-1}=\left\{t \in[0,1], \phi^{-1}\left(\left|x_{2}(t)\right| \leq \delta\right\},\right. \\
& \Delta_{2, n-1}=\left\{t \in[0,1], \phi^{-1}\left(\left|x_{2}(t)\right|\right)>\delta\right\}
\end{aligned}
$$

and

$$
g_{\delta, n-1}=\max _{\left.t \in[0,1], \phi^{-1}\left|x_{2}\right|\right) \leq \delta} \mid g_{i}\left(t, \phi^{-1}(x) \mid .\right.
$$

Then

$$
\begin{aligned}
\frac{1}{2}\left(x_{2}(t)\right)^{2} \leq & \sum_{i=0}^{n-2} \int_{\Delta_{1, i}}\left|g_{i}\left(s, x_{1}^{(i)}(s)\right)\right|\left|x_{2}(s)\right| d s \\
& +\sum_{i=0}^{n-2} \int_{\Delta_{2, i}}\left|g_{i}\left(s, x_{1}^{(i)}(s)\right)\right|\left|x_{2}(s)\right| d s \\
& +\int_{\Delta_{1, n-1}}\left|g_{i}\left(s, \phi^{-1}\left(x_{2}(s)\right)\right)\right|\left|x_{2}(s)\right| d s \\
& +\int_{\Delta_{2, n-1}}\left|g_{i}\left(s, \phi^{-1}\left(x_{2}(s)\right)\right)\right|\left|x_{2}(s)\right| d s \\
& +\int_{0}^{1}\left|e(s) \| x_{2}(s)\right| d s \\
\leq & \sum_{i=0}^{n-2} g_{\delta, i}\left\|x_{2}\right\|+\sum_{i=0}^{n-2}\left(r_{i}+\varepsilon\right) \phi\left(\left\|x_{1}^{(i)}\right\|\right)\left\|x_{2}\right\|+g_{1, n-1}\left\|x_{2}\right\| \\
& +\left(r_{n-1}+\varepsilon\right)\left\|x_{2}\right\|^{2}+\|e\|\left\|x_{2}\right\| .
\end{aligned}
$$

Hence

$$
\begin{aligned}
\frac{1}{2}\left\|x_{2}\right\|^{2} \leq & \left(\sum_{i=0}^{n-1} g_{\delta, i}+\|e\|\right)\left\|x_{2}\right\| \\
& +\sum_{i=0}^{n-2}\left(r_{i}+\varepsilon\right) \phi\left(\left\|x_{1}^{(i)}\right\|\right)\left\|x_{2}\right\|+\left(r_{n-1}+\varepsilon\right)\left\|x_{2}\right\|^{2} .
\end{aligned}
$$


On the other hand, for $i=0, \ldots, n-3$, we have

$$
\begin{aligned}
& \left|x_{1}^{(i)}(t)\right|=\left|x_{1}^{(i)}(0)+\int_{0}^{t} x_{1}^{(i+1)}(s) d s\right| \\
& \leq \int_{0}^{1}\left|x_{1}^{(i+1)}(s)\right| d s \leq \int_{0}^{1}\left|x_{1}^{(n-2)}(s)\right| d s .
\end{aligned}
$$

Then

$$
\left\|x_{1}^{(i)}\right\| \leq\left\|x_{1}^{(n-2)}\right\|, \quad i=0, \ldots, n-2 .
$$

It follows from (12) that

$$
x_{2}^{\prime}(t)=\lambda f\left(t, x(t), \ldots, x^{(n-2)}(t), \frac{1}{\lambda} x^{(n-1)}(t)\right) .
$$

Then

$$
\begin{aligned}
& \int_{0}^{1} f\left(t, x_{1}(t), \ldots, x_{1}^{(n-2)}(t), \frac{1}{\lambda} x_{1}^{(n-1)}(t)\right) d t \\
& -\sum_{i=1}^{m} \alpha_{i} \int_{0}^{\eta_{i}} f\left(t, x_{1}(t), \ldots, x_{1}^{(n-2)}(t), \frac{1}{\lambda} x_{2}^{(n-1)}(t)\right) d t=0 .
\end{aligned}
$$

Hence we get from $\left(A_{5}\right)$ that there is $t_{0} \in[0,1]$ so that $\left|x_{1}^{(n-2)}\left(t_{0}\right)\right| \leq M$. Then we have

$$
\begin{aligned}
\left|x_{1}^{(n-2)}(t)\right| & \leq\left|x_{1}^{(n-2)}\left(t_{0}\right)+\int_{t_{0}}^{t} x^{(n-1)}(s) d s\right| \\
& \leq M+\left\|x^{(n-1)}\right\| \leq M+\phi^{-1}\left(\left\|x_{2}\right\|\right) .
\end{aligned}
$$

It follows from (14) that

$$
\begin{aligned}
\frac{1}{2}\left\|x_{2}\right\|^{2} \leq & \left(\sum_{i=0}^{n-1} g_{\delta, i}+\|e\|\right)\left\|x_{2}\right\| \\
& +\sum_{i=0}^{n-2}\left(r_{i}+\varepsilon\right) \phi\left(M+\phi^{-1}\left(\left\|x_{2}\right\|\right)\right)\left\|x_{2}\right\|+\left(r_{n-1}+\varepsilon\right)\left\|x_{2}\right\|^{2} \\
\leq & \left(\sum_{i=0}^{n-1} g_{\delta, i}+\|e\|\right)\left\|x_{2}\right\| \\
& +\sum_{i=0}^{n-2}\left(r_{i}+\varepsilon\right) \mu\left(\phi(M)\left\|x_{2}\right\|+\mu\left\|x_{2}\right\|^{2}\right)+\left(r_{n-1}+\varepsilon\right)\left\|x_{2}\right\|^{2} .
\end{aligned}
$$

It follows that

$$
\left[\frac{1}{2}-\sum_{i=0}^{n-2} \mu\left(r_{i}+\varepsilon\right)+\left(r_{n-1}+\varepsilon\right)\right]\left\|x_{2}\right\|
$$




$$
\leq\left(\sum_{i=0}^{n-1} g_{\delta, i}+\|e\|\right)\left\|x_{2}\right\|+\sum_{i=0}^{n-2}\left(r_{i}+\varepsilon\right) \mu \phi(M)\left\|x_{2}\right\|
$$

We get there is $\bar{M}>0$ such that $\left\|x_{2}\right\| \leq \bar{M}$. It follows from (16) that

$$
\left\|x_{1}^{(i)}\right\| \leq M+\phi^{-1}\left(\left\|x_{2}\right\|\right) \leq M+\phi^{-1}(\bar{M}), \quad i=0, \ldots, n-2 .
$$

It follows that there is $B>0$ so that $\left\|\left(x_{1}, x_{2}\right)\right\| \leq B$. It follows that $\Omega_{1}$ is bounded.

Step 2. Let $\Omega_{2}=\left\{x \in \operatorname{Ker} L_{2}: N x \in \operatorname{Im} L_{2}\right\}$. For $x \in \Omega_{2}$, then $x(t)=\left(a t^{n-2}, 0\right)$ for some $a \in R$. Hence $N x=\left(0, f\left(t, a t^{n-2}, a(n-\right.\right.$ $\left.\left.2) t^{n-3}, \ldots, a(n-2) !, 0\right), 0, \ldots, 0\right) \in \operatorname{Im} L_{2}$ implies that there are functions $u_{1}, u_{2}$ and $u_{3}$ so that

$$
\begin{aligned}
& \begin{cases}u_{1}^{(n-1)}(t)=0, & 0<t<t<1, \\
u_{2}^{\prime}(t)=f\left(t, a t^{n-2}, a(n-2) t^{n-3}, \ldots, a(n-2) !, 0\right), & 0<t<1,\end{cases} \\
& \begin{cases}u_{1}^{(i)}(0)=0, & i=0, \ldots, n-3, \\
u_{2}(0)=0, & \\
u_{2}(1)-\sum_{i=1}^{l} \beta_{i} u_{2}\left(\eta_{i}\right)=0 .\end{cases}
\end{aligned}
$$

Then

$$
\begin{aligned}
& \int_{0}^{1} f\left(t, a t^{n-2}, a(n-2) t^{n-3}, \ldots, a(n-2) !, 0\right) d t \\
& -\sum_{i=1}^{l} \beta_{i} \int_{0}^{\eta_{i}} f\left(t, a t^{n-2}, a(n-2) t^{n-3}, \ldots, a(n-2) !, 0\right) d t=0 .
\end{aligned}
$$

If $a>M^{*}$, from $\left(A_{7}\right)$, we get

$$
\begin{aligned}
& a\left[\int_{0}^{1} f\left(t, a t^{n-2}, a(n-2) t^{n-3}, \ldots, a(n-2) !, 0\right) d t\right. \\
& \left.-\sum_{i=1}^{l} \beta_{i} \int_{0}^{\eta_{i}} f\left(t, a t^{n-2}, a(n-2) t^{n-3}, \ldots, a(n-2) !, 0\right) d t\right] \neq 0,
\end{aligned}
$$

a contradiction. If $a<-M$, the same contradiction can be induced. Hence $|a| \leq M$. This implies that $\Omega_{2}$ is bounded.

Step 3. If the first part of $\left(A_{7}\right)$ holds, let

$$
\Omega_{3}=\left\{x \in \operatorname{Ker} L_{2}: \lambda \operatorname{sgn}(\Delta) \wedge x+(1-\lambda) Q N x=0, \lambda \in[0,1]\right\} .
$$

We will prove that $\Omega_{3}$ is bounded. For $x=\left(a t^{n-2}, 0\right) \in \Omega_{3}$, we get

$$
\operatorname{sgn}(\Delta) \Delta \lambda_{n} a^{2}=-\left(1-\lambda_{n}\right) a
$$




$$
\begin{aligned}
& \times\left[\int_{0}^{1} f\left(t, a t^{n-2}, a(n-2) t^{n-3}, \ldots, a(n-2) !, 0\right) d t\right. \\
& \left.-\sum_{i=1}^{l} \beta_{i} \int_{0}^{\eta_{i}} f\left(t, a t^{n-2}, a(n-2) t^{n-3}, \ldots, a(n-2) !, 0\right) d t\right]
\end{aligned}
$$

If $|a|>M^{*}$, from $\left(A_{7}\right)$, we see that $\operatorname{sgn}(\Delta) \Delta \lambda_{n} a^{2}<0$, a contradiction. If the second inequality of $\left(A_{7}\right)$ holds, let

$$
\Omega_{3}=\left\{x \in \operatorname{Ker} L_{2}:-\lambda \operatorname{sgn}(\Delta) \wedge x+(1-\lambda) Q N x=0, \lambda \in[0,1]\right\} .
$$

Similarly, we can get a contradiction. So $\Omega_{3}$ is bounded.

The remainder of the proof is just similar to that of the proof of Theorem 2.1 and is omitted. This completes the proof.

Remark. It is easy to see that Theorem 2.1, Theorem 2.1' and Theorem 2.2, by comparing them with results (Theorem LY1, Theorem LY2, Theorem G and Theorem GH) mentioned in Section 1, complement and improve known results in [13], [14], [15], [16] and [5], [9]. For $n=2$, Garcia-Huidobro, Gupta and Manasevich in [6] studies BVP (4)-(5) and BVP (4)-(6) in the case $\sum_{i=1}^{l} \beta_{i}=1$, but all $\beta_{i}$ are required to be nonnegative. However, in this paper, $\beta_{i}$ can be negative or positive.

\section{Numerical EXAMPLES}

In this section, three numerical examples are studied to demonstrate the results of the present method.

Example 3.1. Consider the multi-point boundary value problem

$$
\left\{\begin{array}{l}
x^{\prime \prime}(t)=-2\left[x^{\prime}(t)\right]^{3}+\frac{1}{3} x^{\prime}(t)+\frac{1}{7} x(t)+t+\sin t, \quad 0<t<1 \\
x^{\prime}(0)=x^{\prime}(1)+0.25 x^{\prime}(0)-2.6347 x^{\prime}\left(\frac{4}{5}\right)=0
\end{array}\right.
$$

where $\theta=2, \beta_{1}=-1 / 4, \beta_{2}=5 / 4$ and $\eta_{1}=0, \eta_{2}=4 / 5$ with $\sum_{i=1}^{l} \beta_{i}=1$ and $\sum_{i=1}^{l} \beta_{i} \eta_{i}=1, p(t)=1 / 3, q(t)=1 / 7, r(t)=t+\sin t$. It is easy to check that $\left(A_{2}\right),\left(A_{4}\right),\left(A_{5}\right),\left(A_{6}\right),\left(A_{7}\right)$ and $(11)$ hold. Then, from Theorem 2.2, BVP (17) has at least one solution (see Figure 1. Solution of system (17)). 
The numerical results are given in the following table.

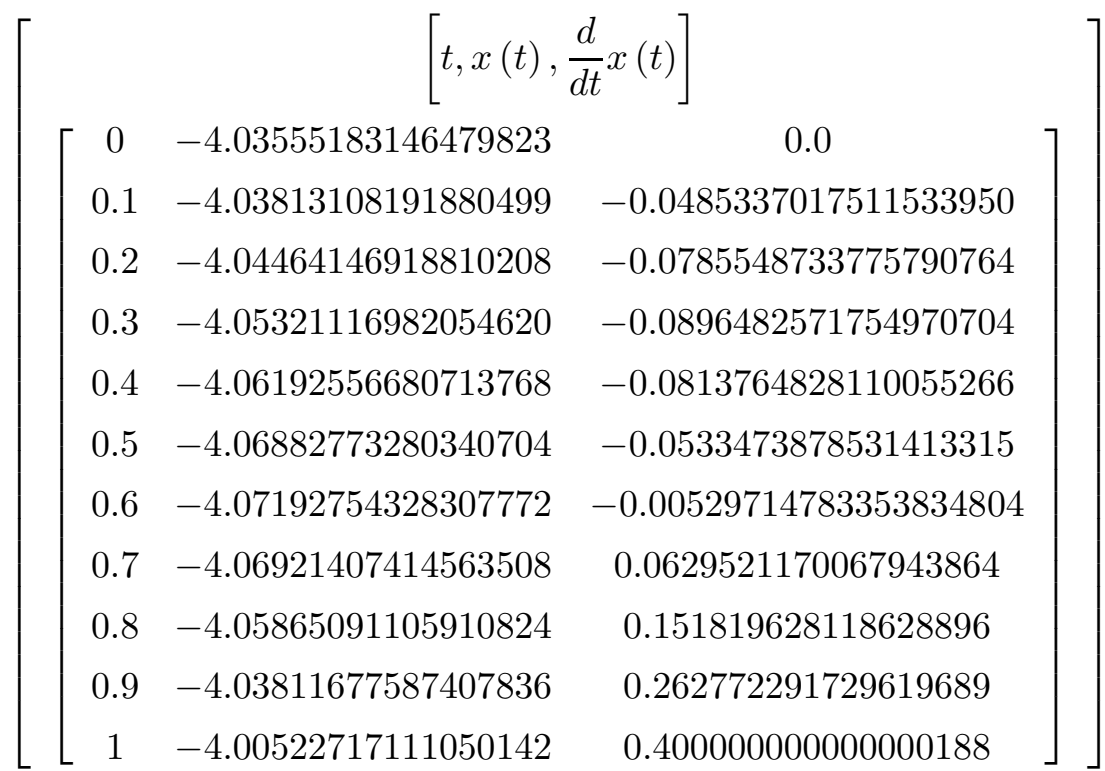

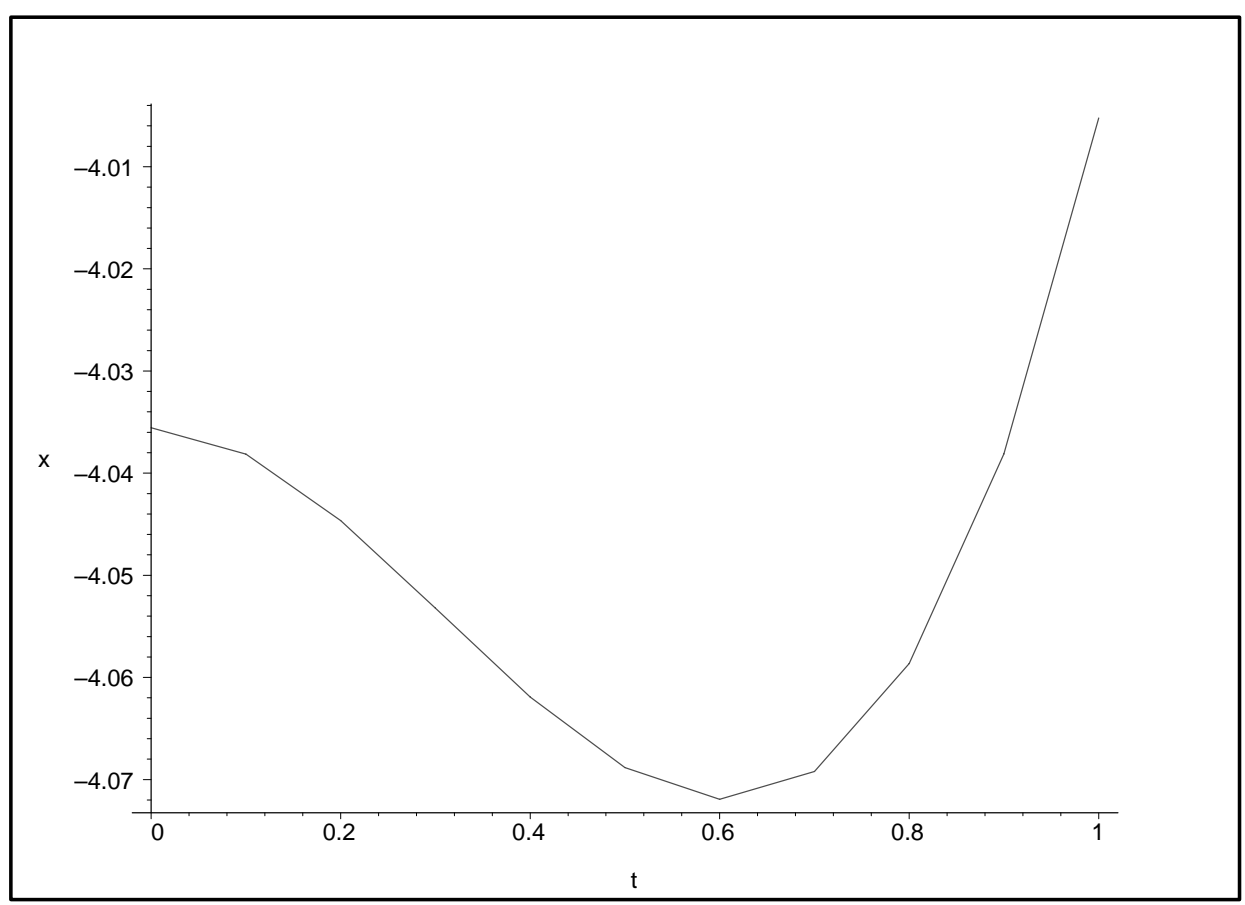

Figure 1. Solution of system (17) 
Example 3.2. Consider the problem

$$
\left\{\begin{array}{l}
x^{\prime \prime}(t)=\frac{1}{2} x^{\prime}(t)+\frac{1}{4} x(t)+2 \cos t, \quad 0<t<1 \\
x(0)=x^{\prime}(1)+x^{\prime}\left(\frac{1}{2}\right)-2 x^{\prime}\left(\frac{3}{4}\right)=0 .
\end{array}\right.
$$

It is easy to check that $\left(A_{1}\right),\left(A_{2}\right),\left(A_{3}\right)$ and (9) hold. Then, from Theorem 2.1, BVP (18) has at least one solution (see Figure 2. Solution of system $(18))$.

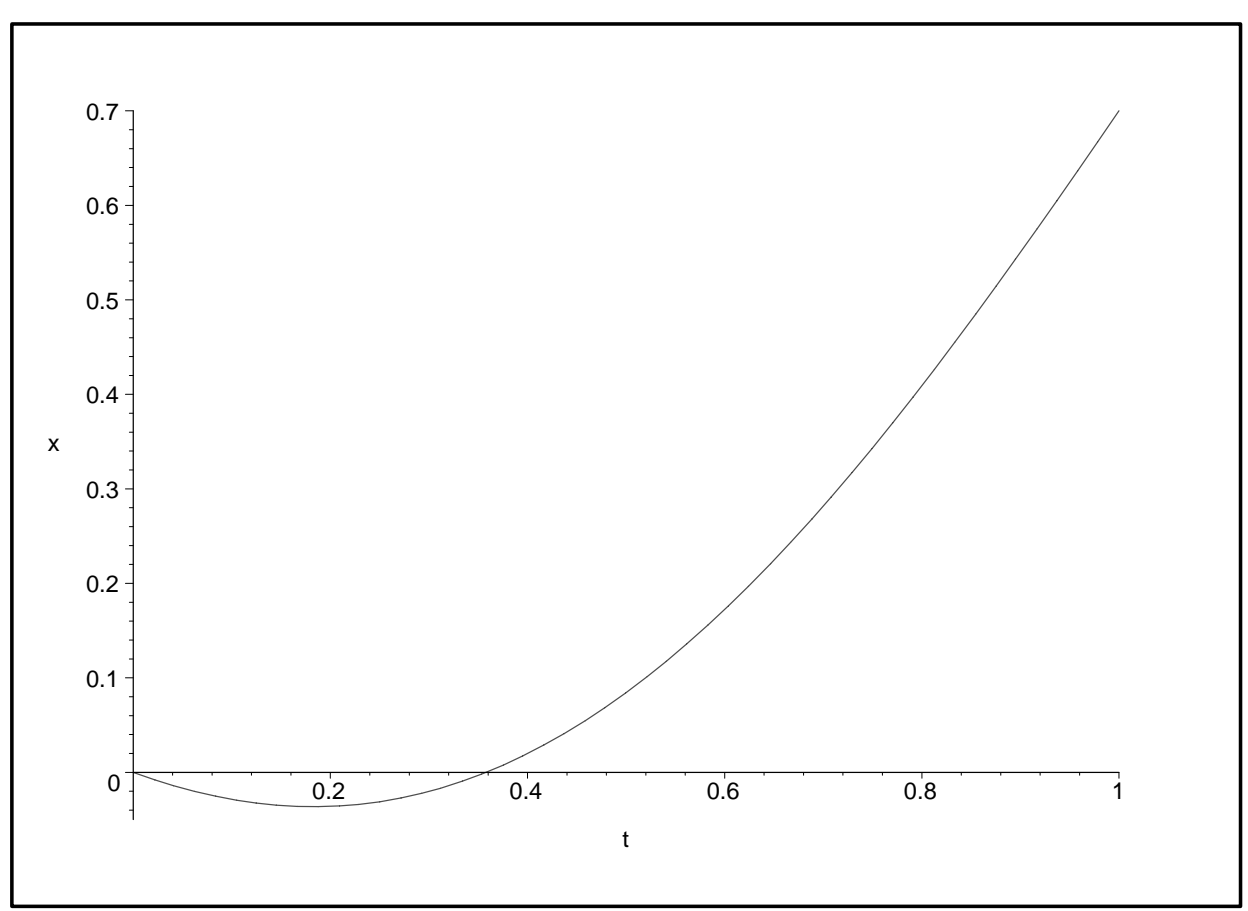

Figure 2. Solution of system (18)

Example 3.3. Consider the problem

$$
\left\{\begin{array}{l}
{\left[\left|x^{\prime}(t)\right|^{3} x^{\prime}(t)\right]^{\prime}=-4\left[\phi\left(x^{\prime}(t)\right)\right]^{3}+\frac{1}{4} \phi\left(x^{\prime}(t)\right)+\frac{1}{5} \phi(x(t))+t^{2},} \\
0<t<1, \\
x^{\prime}(0)=\phi\left(x^{\prime}(1)\right)+\frac{1}{4} \phi\left(x^{\prime}(0)\right)-\frac{7}{4} x^{\prime}\left(\frac{4}{5}\right)=0,
\end{array}\right.
$$

where $\phi(x)=|x|^{3} x, \theta=4, \beta_{1}=-1 / 4, \beta_{2}=7 / 4$ and $\eta_{1}=0, \eta_{2}=4 / 5$, $p(t)=1 / 4, q(t)=1 / 5, r(t)=t^{2}$. It is easy to check that $\left(A_{2}\right),\left(A_{4}\right),\left(A_{5}\right)$, 
$\left(A_{6}\right),\left(A_{7}\right)$ and (11) hold. Then, from Theorem 2.2, BVP (19) has at least one solution (see Figure 3. Solution of system (19)).

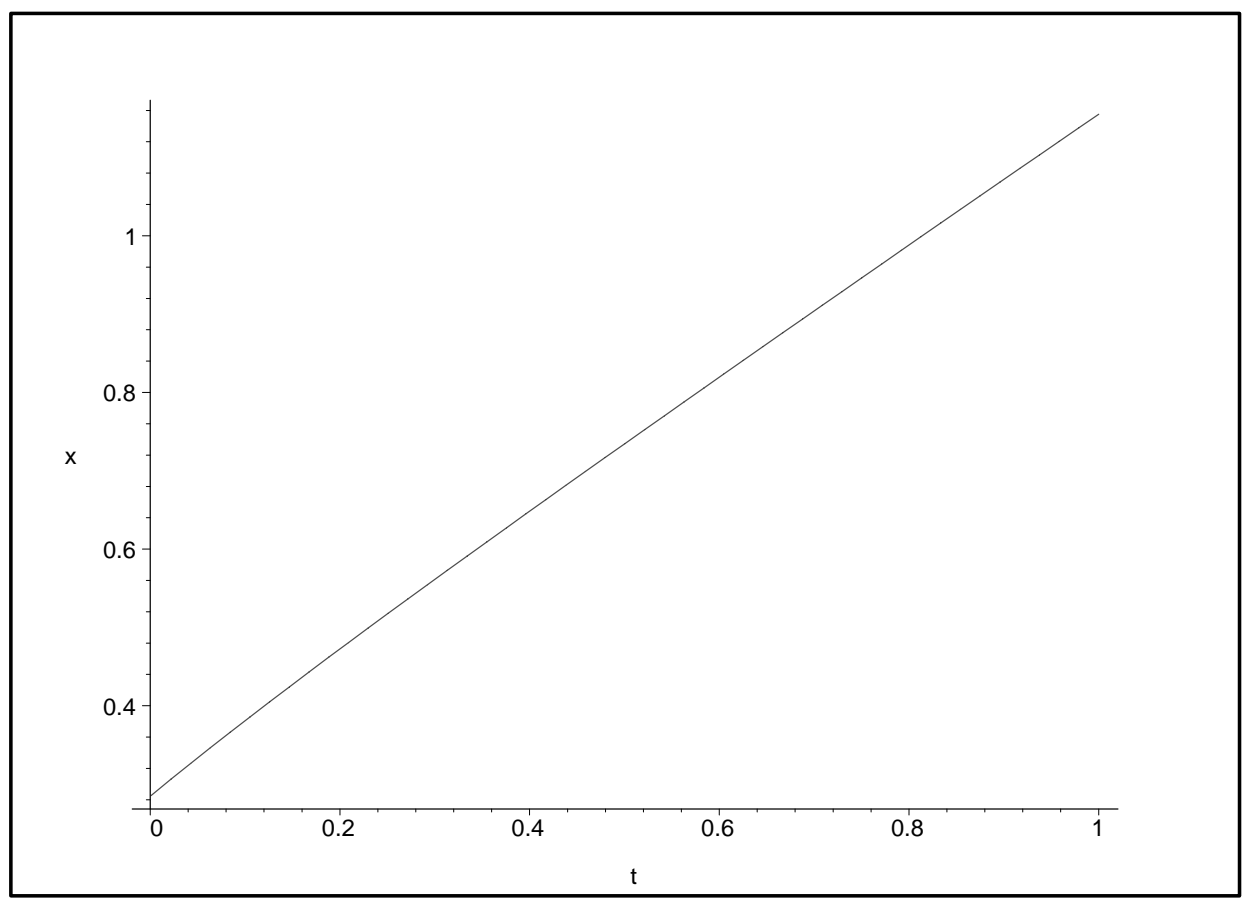

Figure 3. Solution of system (19)

Acknowledgement. The authors are very grateful to the referees for their helpful remarks.

\section{References}

[1] Agarwal, R. P., Boundary Value Problems for Higher Order Differential Equations, World Scientific Publishing Co, Inc., Teaneck, NJ, 1986.

[2] Agarwal, R. P., Focal Boundary Value Problems for Differential and Difference Equations, Kluwer Academic Publishers, Dordrecht, 1998.

[3] Agarwal, R. P., O'Regan, D., Wong, P. J. Y. , Positive Solutions of Differential, Difference and Integral Equations, Kluwer Academic Publishers, Dordrecht, 1999.

[4] Feng, W., Webb, J. R. L., Solvability of m-point boundary value problems with nonlinear growth, J. Math. Anal. Appl. 212 (1997), 467-489.

[5] Garcia-Huidobro, M., Gupta, C. P., Manasevich, R., An m-point boundary value problem of Neumann type for p-Laplacian like operator, Nonlinear Anal. 56 (2004), 1071-1089. 
[6] Garcia-Huidobro, M., Gupta, C. P., Manasevich, R., A Dirichelet-Neumann m-point BVP with a p-Laplacian-like operator, Nonlinear Anal. 62 (2005), 1067-1089.

[7] Gupta, C. P., Solvability of a three-point nonlinear boundary value problem for a second order ordinary differential equation, J. Math. Anal. Appl. 168 (1992), 540551.

[8] Gupta, C. P., A sharper conditions for the solvability of three-point second order boundary value problem, J. Math. Anal. Appl. 205 (1997), 579-586.

[9] Gupta, C. P., A non-resonant multi-point boundary value problem for a p-Laplacian type operator, Proc. of the Fifth Mississippi State Conference on Differential Equations and Computational Simulations (Mississippi State, MS, 2001), 143-152 (electronic), Electron. J. Differ. Equ. Conf. 10 (2003).

[10] Il'in, V., Moiseev, E., Non-local boundary value problems of first kind for a SturmLiouville operator in its differential and finite difference aspects, Differ. Equ. 23 (1987), 803-810.

[11] Il'in, V., Moiseev, E., Non-local boundary value problems of the second kind for a Sturm-Liouville operator, Differ. Equ. 23 (1987), 979-987.

[12] Lian, W., Wong, F., Existence of positive solutions for higher-order generalized pLaplacian BVPs, Appl. Math. Lett. 13 (2000), 35-43.

[13] Liu, B., Solvability of multi-point boundary value problems at resonance (III), Appl. Math. Comput. 129 (2002), 119-143.

[14] Liu, B., Solvability of multi-point boundary value problems at resonance (II), Appl. Math. Comput. 136 (2003), 353-377.

[15] Liu, B., Solvability of multi-point boundary value problems at resonance (IV), Appl. Math. Comput. 143 (2003), 275-299.

[16] Liu, B., Yu, J., Solvability of multi-point boundary value problems at resonance (I), Indian J. Pure Appl. Math. 33(4) (2002), 475-494.

[17] Liu, Y., Ge, W., Solvability of a $(p, n-p)$-type multi-point boundary-value problem for higher-order differential equations, Electron. J. Differential Equations 2003(120) (2003), pp. 19 (electronic).

[18] Liu, Y., Ge, W., Solvability of two-point boundary value problems for higher-order ordinary differential equations at resonance, Math. Sci. Res. J. 11 (2003), 406-429.

[19] Liu, Y., Ge, W., Solvability of nonlocal boundary value problems for ordinary differential equations of higher order, Nonlinear Anal. 57 (2004), 435-458.

[20] Liu, Y., Ge, W., Solvability of multi-point boundary value problems for $2 n$-th order ordinary differential equations at resonance. II, Hiroshima Math. J. 35 (2005), 1-29.

[21] Mawhin, J., Topological degree methods in nonlinear boundary value problems, (Expository lectures from CBMS Regional Conference held at Harvey Mudd College, Claremont, CA, 1977), CBMS Regional Conference Series in Mathematics 40, Amer. Math. Soc., Providence, RI, 1979.

[22] Mawhin, J., Topological degree and boundary value problems for nonlinear differential equations (Montecatini Terme, 1991), in: "Topological Methods for Ordinary Differential Equations", Lecture Notes in Math. 1537, Springer, Berlin, 1993. 
YuJI LiU

Department of Mathematics Guangdong University

of Business Studies

GuAngzhou 510320

P. R. CHINA

E-MAIL: LIUYUJI888@SOHU.COM
Zhanji Gui

Department of Computer SCIENCE

HaINAN NoRmal UnIVERSITY

HAIKOU 571158

P. R. CHINA

E-MAIL: ZHANJIGUI@SOHU.COM 